\title{
WISATA HIJAU DAN KEPUASAN WISATAWAN
}

\author{
Lusi Endang Sri Darmawati \\ SMKN 01 PANJI Situbondo \\ Jl. Guning Arjuno 17 Situbondo Jawa Timur
}

Korespodensi dengan Penulis:

Lusi Endang SD: Telp: 081333330101

E-mail: lusiesd@gmail.com

\begin{abstract}
The aim of this research is to examine the influence of green tourism attraction towards tourists' satisfaction. Likert Scale used in this research, which 5 means strongly agree and 1 means strongly disagree. The population for this research consisted of tourists that visiting green tourism object and collected data from a variety of primary sources. The collected data were analyzed using Statistics Programs Social Sciences (SPSS), the independent $t$-test, and simple regression analysis. The results from the regression equation estimation that partly tested for green tourism attraction effect towards the tourist satisfaction showed that the green tourism has a positive and significant effect towards the tourist satisfaction. It means, the better and complete inventory of facilities at the green tourist attractions will improve the quality of green tourism up to $81 \%$. The main factors that influence the satisfaction of the tourists is the availability of green open spaces such as the large number of beautiful and lush plants around tourist attractions.
\end{abstract}

Keywords: Green Tourism, Regression, Tourists

\begin{abstract}
Abstrak
Tujuan dari penelitian ini adalah ingin menguji pengaruh daya tarik wisata hijau terhadap kepuasan wisatawan, Metode penelitian yang di gunakan mengadopsi Skala Likert dari 1 sampai 5 di mana 5 sangat setuju dan 1 sangat tidak setuju. Populasi untuk penelitian ini terdiri dari wisatawan yang berkunjung di wisata hijau, data yang dikumpulkan dari berbagai sumber primer, data yang dikumpulkan dianalisis dengan menggunakan Statistic Program Social Sciences (SPSS). Uji analisis yang digunakan untuk adalah t-test independen dan analisis regresi sederhana. Hasil Penelitian dari estimasi persamaan regresi yang diuji secara parsial tentang pengaruh daya tarik wisata hijau terhadap kepuasan wisatawan adalah secara positif dan signifikan wisata hijau berpengaruh terhadap kepuasan wisatawan, artinya bahwa semakin baik dan lengkap persediaan fasilitas di tempat wisata hijau maka semakin meningkatkan kualitas kepuasan wisatawan di wisata hijausampai sebesar $81 \%$. Faktor utama fasilitas wisata hijau yang berpengaruh pada kepuasan wisatawan adalah tersedianya ruang terbuka hijau seperti banyaknya tanaman yang indah dan rindang di sekitar tempat wisata.
\end{abstract}

Kata Kunci: Wisata Hijau, Regresi, Wisatawan

\section{PENDAHULUAN}

Konsep produk wisata hijau dinyatakan sebagai perjalanan yang bertanggung jawab secara ekologis, mengunjungi wilayah asli, untuk menikmati

Citation: Darmawati, L. (2018). Wisata Hijau Dan Kepuasan Wisatawan. Jurnal Pariwisata Pesona, 3(1). doi:10.26905/jpp.v3i1.2138 
dan menghargai keindahan alam (termasuk budaya lokal) dan mempromosikan konservasi, memiliki efek negatif terkecil dan memberikan peluang bagi komunitas lokal untuk terlibat dalam kegiatan pariwisata, akan tetapi pengembangan wisata hijau belum banyak berkembang di masyarakat, wisata hijau tidak bisa dilaksanakan hanya oleh satu unsur pelaku, pengembangan wisata hijau harus dilakukan oleh semua pihak yang terlibat baik secara langsung maupun tidak langsung dengan kegiatan wisata hijau. Semua pihak yang terkait harus memiliki kepedulian dan komitmen untuk mengimplementasikan pengembangan wisata hijau .

Faktor environmental sustainability merupakan salah satu faktor penentu daya saing pariwisata global. Minimal 3 komponen penentu daya saing pariwsata yaitu tourism service infrastructure, tourism health and hygiene, dan environmental sustainability untuk menjadi Quality tourism destination (QTD) dan menjadi branding dalam memenangkan persaingan bisnis dalam rangka mendatangkan wisatawan (Yahya 2015). Kesadaran wisatawan wisata hijau terhadap pelayanan ramah lingkungan dimulai dari hasil penelitian Crocker (2008) menunjukkan hasil survei perjalanan wisata $85 \%$ wisatawan memiliki tanggungjawab terhadap lingkungan sebagai konsumen hijau dan penelitian Clausing (2008) menemukan $38 \%$ wisatawan telah memilih dan mencari penginapan dengan fasilitas hijau tahun berikutnya dilanjutkan oleh Power (2009) bahwa wisatawan wisata hijau menyatakan puas terhadap bila wisata hijau dikelolah dengan kepedulian terhadap lingkungan.

Fenomena business yang terjadi dan persaingan ketat di industri wisata serta banyaknya hasil penelitian yang mengarah pada pentingnya kepedulian lingkungan maka dapat mendorong terwujudnya praktek wisata hijau secara baik untuk meningkatkan awareness dalam kepedulian lingkungan di tengah iklim pemanasan global, untuk meningkatkan daya saing industri wisata dalam meraih peningkatan jumlah wisatawan dan meningkatkan kualitas layanan wisata, dengan demikian studi ini dibutuhkan untuk mengisi terjadinya kesenjangan bisnis agar ada solusi implikasi bagi para pelaku bisnis wisata 
untuk memahami tren kebutuhan wisatawan hijau yang peduli terhadap lingkungan.

\section{KERANGKA TEORI}

Kepuasan sebagai suatu perbandingan antara harapan dan apa yang dirasakan juga dikemukakan oleh Fecikova (2004:57) yaitu a feeling which results from a process of evaluating what was received agains that expected, the purchase decision itself and/or the fulfillment of need/want. Pendapat tersebut menerangkan bahwa kepuasan merupakan perasaan yang dihasilkan dari mengevaluasi apa yang dirasakan dibandingkan dengan harapannya, yang berkaitan dengan keinginan dan kebutuhan dari konsumen tersebut pada sebuah produk atau layanan. Lebih lanjut Shankar et al. (2003:154) menjelaskan bahwa kepuasan konsumen adalah the perception of pleasurable fulfillment of a service, and loyalty as deep commitment to the service provider. Pengertian tersebut menunjukkan bahwa kepuasan wisatawan lebih mengarah pada sikap dan perilaku loyal, atau ditunjukkan oleh komitmen yang tinggi terhadap perusahaan.

Berdasarkan pendapat para pakar tersebut, dapat dinyatakan bahwa kepuasan adalah perasaan senang atau kecewa yang dimiliki seseorang berdasarkan perbandingan antara kenyataan yang diperoleh dengan harapan yang diinginkan oleh wisatawan. Jika barang dan jasa yang dibeli cocok dengan apa yang diharapkan oleh wisatawan, maka akan terdapat kepuasan atau sebaliknya. Apabila kenikmatan yang diperoleh wisatawan melebihi harapannya, maka wisatawan akan betul-betul merasa puas dan sudah pasti wisatawan akan terus mengadakan pembelian ulang serta mengajak teman-temannya sehingga hal itu dapat memberikan keuntungan bagi perusahaan. Wijaya dan Irawati (2004:140) mengemukakan pendapat tentang kepuasan bila : (1) Nilai harapan sama dengan nilai persepsi maka wisatawan puas; (2) Nilai harapan lebih rendah daripada nilai persepsi maka wisatawan sangat puas; (3) Nilai harapan lebih tinggi daripada nilai persepsi maka wisatawan tidak puas. Maksudnya, kepuasan adalah perasaan senang atau kecewa seseorang yang muncul setelah membandingkan antara persepsi/kesannya terhadap kinerja (atau hasil) suatu produk dan harapan-harapannya. Kepuasan seorang 
pembeli (wisatawan) setelah melakukan pembelian tergantung pada kesesuaian antara prestasi dari produk yang dibeli dengan harapan dari pembelian tersebut. Dengan demikian dapat diartikan bahwa kepuasan wisatawan merupakan perbedaan antara yang diharapkan wisatawan (nilai harapan) dengan situasi yang diberikan perusahaan di dalam usaha memenuhi harapan wisatawan. .

Wisata hijau merupakan produk hijau bagian dari kegiatan Green Marketing yang dapat dimaknai sebagai produk yang dikemas untuk mengurangi dampakdampak lingkungan yang diakibatkan proses produksi (Albino, 2009;85), sedang praktek Wisata hijau apabila digunakan di industri wisata hijau dapat dikatakan sebagai green wisata hijau (Lu, 2013). Wisata hijau ini mencakup sejumlah kriteria dan persyaratan utama: 1). Kebijakan lingkungan dan aktivitas pengoperasian wisata hijau, 2). Pemanfaatan dan penggunaan green attraction, 3). Kerjasama dengan masyarakat dan organisasi lokal, 4). Human resources development, 5). Solid waste management, 6). Energy efficiency, 7). Water efficiency, 8). Air quality management (indoor and outdoor), 9). Noise pollution control,10). Waste water treatment and management, 11). Toxic and chemical substance disposal management (USAID,2015).

Sebagai standar penilaian kebijakan pemerintah dalam hal ini adalah Dirjen Pengembangan Destinasi Pariwisata kementerian pariwisata (Firmansyah, 2013) mengatakan untuk menentukan Green attraction sebuah wisata hijau terdapat 10 kriteria penilaian yang meliputi, tata guna lahan, penggunaan energi, konservasi air, material ramah lingkungan, kualitas udara, tata kelola bangunan (pengelolaan limbah), green purchasing, management wisata hijau, food management dan corporate sosial responsibility (CSR).

Kerterkaitan konsepsi wisata hijau terhadap Kepuasan Konsumen terurai dalam penelitiannya Boztepe (2012) menjelaskan bahwa salah satu unsur green marketing yaitu wisata hijau memiliki pengaruh terhadap kepuasan konsumen, diperkuat lagi dari hasil penelitan Yazdanifard et al. (2011), menjelaskan bahwa Green attraction berdampak positif pada peningkatan kepuasan konsumen, dan menurut Bukhari (2013); Nanny (2016) bahwa Green attraction berpengaruh pada kepuasan pembelian konsumen dan perusahaan 
bisa mendapatkan keunggulan kompetitif apabila mengadopsi konsep green attraction ini. Adapun indikator Green attraction telah dikemukakan oleh Dangelico (2010) yaitu: Daur ulang produk, produk dapat digunakan kembali, efisiensi sumber daya, dan terhindar dari bahan berbahaya.

\section{METODE}

Data diperoleh dari kuesioner yang mengadopsi Skala Likert dari 1 sampai 5 di mana 5 sangat setuju dan 1 sangat tidak setuju. Populasi untuk penelitian ini terdiri dari wisatawan di wisata hijau, responden untuk penelitian ini adalah 100 yang digunakan untuk analisis ini dan responden telah dijemput secara acak untuk membuat kuesioner lebih mudah untuk dijawab. Penelitian ini bertujuan untuk menguji hipotesis bahwa wisata hijau memiliki pengaruh positif dan signifikan terhadap kepuasan wisatawan

Data yang dikumpulkan dari berbagai sumber asli (primer) menjadi sasaran berbagai alat statistik untuk verifikasi dan interpretasi, seperti, Statistik Deskriptif (Rata-Rata, Standar Deviasi dan Persentil) digunakan untuk memiliki pemahaman atas dasar kelompok responden. Data yang pernah dikumpulkan dianalisis dengan menggunakan Statistic Program Social Sciences (SPSS). Tes yang digunakan untuk analisis adalah t-test independen dan analisis regresi sederhana (Rawlings 1998)

\section{HASIL DAN PEMBAHASAN}

Hasil

Tanggapan responden tentang wisata hijau pada indikator reused product $(\mathrm{n}=100)$ dari setiap item pernyataan sebagai berikut: (a) Wisatawan wisata hijau memanfaatkan fasilitas kebutuhan sovenir yang tersedia daur ulang, terdapat $10.3 \%$ responden menjawab sangat setuju, $73.5 \%$ setuju, $16.2 \%$ netral, dan yang menjawab tidak setuju atau sangat tidak setuju tidak ada. Nilai rata-rata pada item ini sebesar 3,96 yang bermakna, responden cenderung setuju bahwa wisatawan wisata hijau memanfaatkan fasilitas kebutuhan sovenir yang tersedia daur ulang.

(b) Wisatawan wisata hijau memanfaatkan fasilitas pemilahan sampah organik dan non organik, terdapat $15,0 \%$ responden menjawab sangat setuju, $64.2 \%$ setuju, 
20,8\% netral, dan yang menjawab tidak setuju atau sangat tidak setuju tidak ada. Nilai rata-rata pada item ini sebesar 3,89 yang bermakna, responden cenderung setuju bahwa Wisatawan wisata hijau memanfaatkan fasilitas kebutuhan pemilahan sampah organik dan non. Nilai rata-rata indikator reuse products yaitu sebesar 3.95 yang bermakna bahwa responden cenderung setuju bila wisata hijau menyediakan kebutuhan kebutuhan sovenir yang tersedia daur ulang, dengan demikian bahwa wisata hijau menyediakan kebutuhan sovenir yang tersedia daur ulang memiliki kontribusi pada indikator reuse products, hal utama yang memiliki kontribusi terbesar atau yang memiliki rata-rata item terbesar pada indikator reuse products adalah menyediakan kebutuhan sovenir yang tersedia daur ulang.

Tanggapan responden pada indikator kualitas udara dari setiap item pernyataan sebagai berikut: Tempat wisata hijau menyediakan ruang terbuka hijau (Tanaman vegetasi), terdapat $12.3 \%$ responden menjawab sangat setuju, $63.8 \%$ setuju, 23,8\% netral, dan yang menjawab tidak setuju atau sangat tidak setuju tidak ada. Nilai rata-rata pada item ini sebesar 3,88 yang bermakna, responden cenderung setuju bahwa wisata hijau menyediakan ruang terbuka hijau (Tanaman vegetasi ) yang berada di sekeliling wisata hijau .

Kepuasan Wisatawan dalam penelitian ini meliputi perasaan ingin kembali, dan tidak ada keluhan. Data mengenai deskripsi jawaban responden tentang kepuasan wisatawan .

Tanggapan responden pada indikator perasaan ingin kembali lagi dari setiap item pernyataan sebagai berikut:

(a) Wisatawan wisata hijau akan kembali berkunjung di wisata hijau ini lagi (green wisata hijau ), terdapat $36.9 \%$ responden menjawab sangat setuju, $53.8 \%$ setuju, 9.2\% netral, dan yang menjawab tidak setuju atau sangat tidak setuju tidak ada. Sedangkan nilai rata-rata pada item ini sebesar 4.27 yang bermakna, responden cenderung setuju bahwa Wisatawan wisata hijau akan kembali berkunjung di wisata hijau ini lagi.

(b) Wisatawan akan menambah hari berkunjung di wisata hijau, terdapat $33.1 \%$ responden menjawab sangat setuju, 55.4\% setuju, 11.5\% netral, dan yang menjawab tidak setuju atau sangat tidak setuju tidak ada. Sedangkan nilai rata-rata pada item 
ini sebesar 4.21 yang bermakna, responden cenderung setuju bahwa Wisatawan wisata hijau bersedia untuk berkunjung lebih lama atau menambah lama berkunjung di wisata hijau lagi.

Tanggapan responden pada indikator tidak ada komplain dari setiap item pernyataan sebagai berikut:

(a) Selama tingggal di wisata hijau wisatawan tidak pernah mengeluh terhadap pelayanan yang diberikan di wisata hijau, terdapat $36.5 \%$ responden menjawab sangat setuju, 50.5\% setuju, 13,1\% netral, dan yang menjawab tidak setuju atau sangat tidak setuju tidak ada. Sedangkan nilai rata-rata pada item ini sebesar 4.25 yang bermakna, responden cenderung setuju bahwa Selama tingggal di wisata hijau wisatawan tidak pernah mengeluh terhadap pelayanan yang diberikan oleh di wisata hijau .

(b) Selama berkunjung di wisata hijau wisatawan senantiasa memberi reword dalam bentuk tip kepada karyawan wisata hijau sebagai imbalan jasa pelayanan, terdapat $45.4 \%$ responden menjawab sangat setuju, $47.7 \%$ setuju, $6.9 \%$ netral, dan yang menjawab tidak setuju atau sangat tidak setuju tidak ada. Sedangkan nilai ratarata pada item ini sebesar 4.38 yang bermakna, responden cenderung setuju bahwa Selama berkunjung di wisata hijau wisatawan senantiasa memberi reword dalam bentuk tip kepada karyawan wisata hijau sebagai imbalan jasa pelayanan.

Berdasarkan hasil analisis statistik regresi diperoleh model sebagai berikut: $\mathrm{Y}=1,16+0,815 \mathrm{X}_{1}$. Hasil perhitungan, Regression Coefficients $\mathrm{X}_{1}$ adalah 0,815 dengan arti jika wisata hijau meningkat sebesar satu satuan maka akan menyebabkan Kepuasan wisatawan meningkat sebesar 81,5\% di wisata hijau Batu Jawa Timur dan sebaliknya menurunnya wisata hijau sebesar satu satuan akan menyebabkan menurunnya Kepuasan wisatawan sebesar 81,5\%. Variabel wisata hijau memiliki $\mathrm{t}$ tes $(8,408)$, pada taraf level of significant $95 \% \mathrm{H}_{0}$ ditolak artinya bahwa ada pengaruh variabel wisata hijau terhadap variabel Kepuasan wisatawan di wisata hijau Batu Jawa Timur. Hasil regresi yang diperoleh correlations coefficients lebih dari 0.7 artinya hubungan antara wisata hijau dan kepuasan wisatawan kuat. 


\section{Pembahasan}

Hasil analisis menunjukkan gambaran bahwa wisata hijau dipersepsikan melalui indikator: reuse product dan kualitas udara. Indikator tersebut dapat memberikan refleksi positif terhadap green attraction atau produk hijau yang merupakan upaya perancangan barang atau jasa untuk meminimalkan dampak lingkungan selama siklus produksi di wisata hijau, produk wisata hijau yang dirancang untuk meminimalkan dampak lingkungan disebut wisata hijau . Pengukuran indikator tersebut sudah sesuai apa yang telah dijelaskan oleh Dangelico (2010); Albino (2009); Supriadi (2017), menyebutkan bahwa dimensidimensi untuk mengukur wisata hijau adalah indikator reuse products, kualitas udara, dan efisiensi air, sehingga pendapat tersebut tentang indikator pembentuk green attraction telah mendukung hasil penelitian kali ini.

Oleh karena itu wisata hijau mencerminkan nilai-nilai pengalaman wisatawan selama di wisata hijau yang mencakup gairah sensorik kesenangan wisatawan terhadap kepeduliaan lingkungan. Selain dari Dangelico (2010) faktor-faktor pelestarian lingkungan (penggunaan air dan energi, bahan berbahaya, polusi, dan bahan daur ulang) yang memberikan kontribusi terhadap wisata hijau yang disampaikan oleh Kaur (2014); Saini (2013); Boztepe (2012); Bukhari (2011); Albino (2010) dan Supriadi (2016), telah mendukung terhadap hasil penelitian kali ini.

\section{KESIMPULAN}

Penilaian wisatawan terhadap kualitas wisata hijau telah dimotivasi oleh keinginan wisatawan akan kepedulian lingkungan atau praktek ramah lingkungan pada operasional wisata hijau di Batu Jawa Timur. Berdasarkan persepsi dari responden dinyatakan bahwa dari indikator tersebut bahwa minimalisasi udara merupakan hal utama dalam memberi kontribusi pada variabel wisata hijau.

Wisata hijau dikontribusi oleh beberapa faktor yaitu Reused product, dan kualitas udara, indikator pembentuk utama wisata hijau adalah kualitas udara, hal ini dikarenakan wisatawan di wisata hijau Batu Jawa Timur memahami terhadap wisata yang memiliki kualitas udara melalui fasilitas ruang terbuka hijau (Tanaman 
vegetasi ) selama berkunjung, dan wisatawan wisata hijau berharap terhadap wisata hijau untuk menyediakan ruang terbuka hijau (Wisata tanaman vegetasi ).

Hasil analisis regresi diperoleh bahwa wisata hijau memiliki pengaruh kuat terhadap kepuasan wisatawan artinya, apabila wisata hijau meningkat sebesar satu satuan maka akan menyebabkan kepuasan wisatawan meningkat sebesar $81,5 \%$ di wisata hijau dan sebaliknya menurunnya wisata hijau sebesar satu satuan akan menyebabkan menurunnya kepuasan wisatawan sebesar 81,5\%. Wisata hijau memiliki t tes $(8,408)$ artinya bahwa ada pengaruh variabel wisata hijau terhadap Kepuasan wisatawan di wisata hijau. Hasil regresi yang diperoleh correlations coefficients lebih dari 0.70 (70\%) artinya hubungan antara wisata hijau dan kepuasan wisatawan kuat.

\section{DAFTAR RUJUKAN}

Albino, V., Balice, A., Dangelico, RM., 2009, Environmental strategies and green product development: the behaviours of sustainability-driven companies. Business Strategy and the Environment, 18(2), 83-96.

Boztepe Aysel, 2012, Green Marketing and Its Impact on Consumer Buying Behavior, European Journal of Economic and Political Studies,ejeps-5 (1),5-21.

Clausing, J. Survey, 2008, Boomers more likely to go green in business travel. Travel Weekly, 67(2), 22.

Crocker, M., 2008, Among leisure travelers surveyed, nearly everyone professes to be green. Retrieved from

http://apps.travelweekly.com/Multimedia/consumertrends072808/index.h tml. 2008, July 28

Dangelico Rosa Maria, Pierpaolo Pontrandolfo, 2010, From green product definitions and classifications to the Green Option Matrix, Journal of Cleaner Production 18 (2010) 1608e1628.

Fecikova, Ingrid, 2004, An Index Method for Measurement of Customer Satisfaction. TQM Magazine. 16(1):57-68.

Firmansyah Rahim, 2013, http:/ / kemenpar.go.id/asp/detil.asp?c=16\&id=2424, Diakses tanggal 15 Oktober 2015.

Kotler Philip, Keller Kevin Lane., 2012, Marketing Management, Prentice Hall International 14th Edition, One Lake Street, Upper Saddle River, New Jersey 07458, Pearson Education. 
Lu, Carol. Y., 2013, The Effects Of Hedonic And Utilitarian Values On Consumer Behaviors Toward Green Hotel, Advances In Hospitality And Toourism Marketing \& management Conference, ISBN: 978-960-287-139-3.

Millar M, Karl JM, Seyhmus B., 2012, Importance of Green Hotel Attributes to Business and Leisure Travelers, Journal Of Hospitality Marketing E Management, 21:395-413, 2012.

Nanny, R., Supriadi, B., 2016, “Investigasi Green Hotel Sebagai Alternatif Produk Ramah Lingkungan," in GreenTechnology Innovation Proceeding, pp. 1-9.

Power J. D., 2009, North America guest satisfaction study. Retrieved from http://www.jdpower.com/travel/articles/2009-North- America-HotelGuest-Satis faction-Study/page-2.

Saini Babita, 2013, Green marketing and its impact on consumer buying behavior, International Journal of Engineering Science Invention, ISSN (Online): 2319 - 6734, ISSN (Print): 2319 - 6726, www.ijesi.org || Volume 2 Issue 12 | | December. 2013 || PP.61-64.

Shankar, Venkatesh, Amy K. Smith, and Arvind Rangaswamy, 2003, Customer Sastifaction and Loyalty in Online and Offline Environments International. Journal of Research in Marketing, 20(2):153-175. 2003

Soderlund, Magnus., 2013, "The Retrospective and the Prospective Mind and the Temporal Framing of Customer Satisfaction," European Journal of Marketing, 37 (10),1375-1389.

Supriadi, B. and Roedjinanndari, N.,2016, 'Kompetensi pendampingan pemandu wisata lokal sebagai developers of people', Jurnal Pariwisata Pesona, 2(1), pp. 72-86.

Supriadi, B, Widji A., and A. Firdiansyah, 2017, “Green Product And Its Impact on Customer Satisfaction," IOSR J. Bus. Manag., vol. 19, no. 8, p. 19.

Supriadi, B, and Nanny, R., 2016, 'Investigasi Green Hotel Sebagai Alternatif Produk Ramah Lingkungan', GreenTechnology Innovation, International Conference, pp. 1-9. Tjiptono, Fandy, 1997, Strategy Pemasaran, penerbit: Andi offset, Edisi Kedua, Cetakan Pertama, Yogyakarta.

USAID., 2013, Panduan Praktis Efisiensi Energi di Hotel, Indonesia Clean Energy Development (ICED),Jakarta. 2015 [15]. Pangestu Mari Elka, http://kemenpar.go.id/asp/detil.asp?c=16\&id=2424, Diakses tanggal 15 Oktober.

Wijaya, Toni dan Lita Irawati, 2004, Pengaruh persepsi kualitas layanan dan kepuasan konsmen terhadap keinginan pembelian. Jurnal Studi Indonesia, Vol. 14, No.2, September 137 - 150. 
Yahya Arief, 2015, Press conference: Kementeriaan Pariwisawata dalam Anugrah Green Hotel Award 2015 Hotel $_{\llcorner}$ http:/ / kemenpar.go.id/asp/detil.asp?c=16\&id=2985, 5 Oct2015.

Yazdanifard R., 2011, The impact of Green Marketing on Customer satisfaction and Environmental Safety, International Conference on Computer Communication and Management, Proc .of CSIT vol 5, 1ACSIT Press, Singapore. 